\title{
Quality of life of Syrian refugees living in camps in the Kurdistan Region of Iraq
}

The current study explores the perceived quality of life of Syrian refugees who have entered the Kurdistan Region of Iraq. Two hundred and seventy participants residing in refugee camps in the Erbil region in Kurdistan completed the WHOQOL-BREF, which measures Quality of Life (QOL) within four domains; physical, psychological, social relationships and environment. Syrian refugees in Kurdistan scored significantly lower for general population norms on physical health, psychological and environment QOL, and score significantly lower for physical health and psychological QOL for refugees in the Gaza strip. However, respondents in the current sample scored significantly higher on environment QOL compared to refugees in the Gaza strip, and significantly higher on all the QOL domains than those reported for refugees in West Africa. Finally, Syrian refugees in Kurdistan scored significantly higher than general population norms for social relationships QOL. The current findings provide the first report of QOL domain scores among Syrian refugees in the Kurdistan camps and suggest that social relationships and environmental QOL circumstances are relatively satisfactory, and that further investigation might be focused on physical and psychological QOL. 
2 Running head: THE QUALITY OF LIFE OF SYRIAN REFUGEES

3 The Quality of life of Syrian refugees living in camps in the Kurdistan Region of Iraq.

4

5

6

7

8

9

10

11 Acknowledgements: The research was supported by study leave provided by the

12 University of Leicester to John Maltby and Claire Hutchinson.

13 Correspondence concerning this article should be addressed to John Maltby, College of

14 Medicine, Biological Sciences and Psychology, University of Leicester, UK, LE1 9HN. Email,

15 jm148@le.ac.uk.
Aziz, A. Izaddin

University of Leicester, Leicester, United Kingdom.

Claire V. Hutchinson

University of Leicester, Leicester, United Kingdom.

and

John Maltby

University of Leicester, Leicester, United Kingdom. 
Abstract

17 The current study explores the perceived quality of life of Syrian refugees who have entered the

18 Kurdistan Region of Iraq. Two hundred and seventy participants residing in refugee camps in the

19 Erbil region in Kurdistan completed the WHOQOL-BREF, which measures Quality of Life

20 (QOL) within four domains; physical, psychological, social relationships and environment.

21 Syrian refugees in Kurdistan scored significantly lower for general population norms on physical

22 health, psychological and environment QOL, and score significantly lower for physical health

23 and psychological QOL for refugees in the Gaza strip. However, respondents in the current

24 sample scored significantly higher on environment QOL compared to refugees in the Gaza strip,

25 and significantly higher on all the QOL domains than those reported for refugees in West Africa.

26 Finally, Syrian refugees in Kurdistan scored significantly higher than general population norms

27 for social relationships QOL. The current findings provide the first report of QOL domain scores

28 among Syrian refugees in the Kurdistan camps and suggest that social relationships and

29 environmental QOL circumstances are relatively satisfactory, and that further investigation might

30 be focused on physical and psychological QOL.

31 KEY WORDS: Quality of Life, Refugees, Psychological Health, Physical Health, Syria 


\section{PeerJ Reviewing Manuscript}

33 The war in Syria has led to the worst humanitarian crisis of the $21^{\text {st }}$ century. According to United

34 Nations Refugee Agency figures, over 2.5 million people have fled the Syrian conflict, entering

35 as refugees neighboring countries of Turkey, Egypt, Lebanon, Jordan and Iraq. The United

36 Nations Refugee Agency (UNHCR) recorded that by the end of July 2012, 9,503 Syrians had

37 registered as refugees in Iraq who have left Syria for a number of political, economic and social

38 reasons. By the end of February 2013, this number had increased over 10-fold to 102,447

39 (UNHCR, 2013). By February 2014, the figure stood at 225,548 (UNHCR, 2014a) and continues

40 to increase. As of 5th March 2014, 226,934 people had registered as refugees in Iraq. The

41 majority (around $97 \%$ ) are registered in the Kurdistan Region in Northern Iraq, in and around the

42 cities of Duhok (109,979 registered refugees), Erbil (84,881 registered refugees) and

43 Suleimaniyah $(25,134)(\mathrm{UNHCR}, 2014 \mathrm{~b})$. Around $60 \%$ of Syrian refugees are hosted within

44 communities across Kurdistan and the remaining 40\% live in refugee camps (UNHCR, 2014a).

45 When Syrian refugees first began arriving in 2012, most registered in the Directorate of Duhok,

46 near the Peshkhabour border with Syria. This led to the opening of the Domiz camp on 01 April

47 2012. It remains the largest permanent camp with a population of 58,500, as of 28 February 2014.

48 In 2013, as the number of refugees seeking asylum increased, a further four permanent camps

49 were opened in the Directorate of Erbil: Kawergosk (15 August 2013), Qushtapa (19 August

50 2013), Basirma (26 August 2013) and Darashakran (29 Sept 2013), with a combined population

51 of 28,208, as of $28^{\text {th }}$ February 2014 (United Nations Refugee Agency Information Management

52 Unit, 2014).

53 International Aid Agencies are working in collaboration with The Kurdistan Regional

54 Government (KRG) to provide shelter, food, water, healthcare, education and employment for

55 Syrian refugees (UNHCR, 2014c). However, given the sheer numbers of people in need, it is an

56 extremely, and increasingly, difficult situation to manage. Attending, for example, to the complex 


\section{PeerJ Reviewing Manuscript}

57 healthcare needs of such a large population represents a major challenge. The UN Refugee

58 Agency records information from refugees about their physical health complaints and clinical

59 mental health problems at the point of registration but this is almost impossible to monitor on a

60 follow-up basis, given the many challenges and constraints posed by the current crisis. As a

61 result, many psychological issues facing those who live in refugee camps are very unlikely to be

62 addressed or detected.

63 Despite the profound effect of war and forced migration on people's living conditions,

64 surprisingly little attention has been given to the psychological impact of being a refugee. Studies

65 that have investigated this issue have found that the prevalence of psychological illness is

66 relatively high in refugee groups (Gerritsen, et al., 2006). Research suggests that poor perceived

67 present Quality of Life (QOL) may be the most significant factor in psychological illness and

68 stress related disorders in refugee populations (Akinyemi, Owoaje, Ige, \& Popoola, 2012;

69 Carlsson, Olsen, \& Mortensen, 2006; Fazel, Wheeler, \& Danesh, 2005; Matanov, et al., 2013;

70 Tang \& Fox, 2001). These findings support the World Health Organization's position concerning

71 the importance of subjective quality of life as a measure of how an individual perceives "their

72 position in life in the context of the culture and value systems in which they live and in relation to

73 their goals, expectations, standards and concerns" (p.1, World Health Organization, 1997).

74 At present, there is, at least to our knowledge, no data concerning the known perceived

75 QOL of Syrian refugees who have entered the Kurdistan Region of Iraq. These are important

76 issues that, given the sheer scale of the Syrian refugee crisis, have fundamental implications for

77 the future health and well-being of a large number of people. In the present study, we report on

78 the World Health Organization Quality of Life Assessment (WHOQOL-BREF) scores among

79 Syrian refugees living in refugee camps in The Directorate of Erbil, Iraqi-Kurdistan. To provide

80 context to our findings we compare WHOQOL-BREF scores among the current sample to other

81 reports of WHOQOL-BREF scores among other refugee reports. 


\section{Sample}

84 Two hundred and seventy Kurdish nationalist refugees (135 males, 135 females), aged 18 to 60 $85(M=29.26$ years, $S D=9.7)$ from Syria, residing in refugee camps located in Kurdistan took part 86 in the study. The sample used in this study was residing in the Erbil Governorate camps located 87 on four sites: Qushtpa $(n=67)$, Kawrgosk $(n=67)$, Basirma $(n=68)$ and Darashakran $(n=68)$ in 88 January 2014. At each site, the researchers split the map of the site into four zones, with the aim 89 of obtaining around 20 respondents from each zone. In terms of selection and inclusion criteria, 90 the researcher selected the second residence from each alley (moving on to the next residence in

91 that alley if an interview was declined). One member from each family was chosen, who had to

92 be 18 years old or over, and did not have special needs considerations. Equal numbers of

93 respondents were sought from each gender, and to avoid selection bias on the part of the

94 researcher, where there were multiple candidates in any residence for the interview, the individual 95 with the closest birthday to the interview date was chosen.

96 Of these respondents, the most dominant demographic statistics were that $42.6 \%$ of

97 respondents reported highest qualification was having completed secondary education (31.5\% of 98 respondents had completed tertiary education, and $17.4 \%$ of respondents had completed a 99 primary education) and $58.1 \%$ of respondents reported being married (with the next highest

100 frequency being that $40.5 \%$ of respondents were single and $1.9 \%$ of respondents were separated).

\section{Measures}

102 The WHOQOL-BREF is the short 26-item form of the larger WHOQOL-100 assessment (The

103 WHOQOL Group, 1995) that yields four QOL domains: physical health (7 items; e.g. "How

104 much do you need medical treatment to function in your daily life?"), psychological QOL (6 105 items; e.g. "To what extent do you feel life to be meaningful?"), social QOL (3 items; e.g. "How 106 satisfied are you with your personal relationships?"), and environmental QOL (8 items; e.g. "How 
107 safe do you feel in your daily life?"). Responses are scored via five-point response scales with

108 various anchor statements (e.g. from 1 [Very dissatisfied] or [Very poor] to 5 [Very satisfied] or

109 [Very good]). The WHOQOL-BREF can be scored in three ways; through raw scores and two

110 transformation methods; the first that creates domain scores within the range of 4-20, and the

111 second that creates domain scores within the range of 0-100.

112 The WHOQOL-BREF's psychometric properties have been analyzed using cross-

113 sectional data from 11,830 adults from 23 countries (Sevington, Lofty, \& O'Connell, 2004) and is

114 a valid assessment across cultures and socioeconomic status (Hawthorne, Herrman, \& Murphy,

115 2006; Sevington,et al., 2004). Most Syrian refugees in these camps tend to speak the Kurdish

116 language, but have different dialects from the Iraqi Kurdish. However, they are also able to speak

117 the Arabic language. Therefore they were given the Arabic version of the World Health

118 Organization Quality of Life Scale - Brief (WHOQOL-BREF) (Sevington, et al., 2004;

119 WHOQOL group, 1998). The reliability and validity of Arabic versions of the WHOQOL-BREF

120 have been demonstrated among large Arabic-speaking samples (Ohaeri \& Awadalla, 2009). On

121 this occasion, we removed one of the social relationships QOL items ("How satisfied are you

122 with your sex life?") due to concerns over the respondents' potential sensitivity to the question.

123 According to the WHOQOL-BREF manual the transformational methods for scoring of the scale

124 allows for missing items.

\section{Ethics}

126 The study received ethical approval from the University of Leicester's School of Psychology

127 Ethics Board whose ethical procedures conform to those of the British Psychological Society

128 (http://www.bps.org.uk/sites/default/files/documents/code_of_human_research_ethics.pdf). The

129 Ethics Reference for the Ethics Board was jm148-851fa. All participants were 18 years of age or 130 over and provided free and informed consent to take part in the study. Formal procedures and 
131 permission to visit the camps were given by the General Director of Academic Missions and

132 Cultural Relations and the Democracy and Human Rights Research Institute.

133

\section{Results}

134 We found two reports of mean statistics for scores on the WHOQOL-BREF from refugee samples

135 that were not from a clinical population. These reports were from samples from refugee

136 populations residing in West Africa (Akinyemi, et al., 2012) and the Gaza Strip (Eljed,

137 Mikolajcyk, Kramer, \& Laaser, 2006). Together, with the overall norm data for the WHOQOL-

138 BREF from 11,830 adults from 23 countries (Sevington,et al., 2004), these three reports provided

139 information to facilitate statistical mean score comparisons between the current sample and three

140 other samples.

141 Table 1 shows a set of mean comparisons between Syrian refugees in Kurdistan and

142 overall norm data for the WHOQOL-BREF. This comparison uses transformed domain scores

143 within a range 4-20. As our sample data has a missing item, we recomputed the mean/SD score

144 for social relationships QOL for the general population norm data using the frequency responses

145 that have been provided for these two social relationship items (Sevington,et al., 2004). In this

146 table, we also provide effect sizes for the comparisons computed for unequal sample sizes, for

147 which $d>=.8$ represents a large effect size, $.5 \leq d<.8$ represents a moderate effect size, and $.2 \leq$

$148 d<.5$ represents a small effect size (Cohen, 1988). In terms of the comparison with the norm

149 data, the refugees residing in Kurdistan scored significantly lower on physical health, psychology

150 and environment QOL, but significantly higher on social relationships QOL. In terms of effect

151 size, the differences for physical health and psychological QOL are of a large effect size, the

152 differences for the environment QOL are of a moderate effect size, but the difference reported for

153 social relationships QOL does not even meet the criteria of a small effect size. 
Table 2 shows the comparison with the first of the two refugee samples, refugees resident

156 in West Africa (Akinyemi, et al., 2012). For this sample, mean scores were presented as raw

157 scores. Therefore, we have presented mean scores for the Syrian refugees in accordance with this.

158 Across all domains of the QOL scale, the refugees residing in Kurdistan scored significantly

159 higher than those reported in West Africa, with these differences ranging from a moderate effect

160 size (social relationships QOL) to a large effect size (physical health, psychological and

161 environment QOL).

162

- Insert Table 2 about here -

163 Table 3 shows a comparison with a second refugee sample, resident in the Gaza Strip

164 (Eljed, et al. 2006). For this study, mean scores were presented as transformed domain scores

165 with a range $0-100$. Therefore, we have presented the mean scores for the Syrian refugees in

166 accordance with this. For the physical and psychological domains, the refugees residing in

167 Kurdistan scored significantly lower than for those refugees in the Gaza Strip, with these

168 differences being of a large effect size. For the environment QOL domain refugees residing in

169 Kurdistan scored higher than for those refugees in the Gaza Strip with this different being of a

170 moderate effect size. No significant difference was found between Syrian refugees in Kurdistan

171 and refugees residing in the Gaza strip for social relationships QOL.

172

- Insert Table 3 about here -

\section{Discussion}

174 The current findings suggest the QOL among Syrian refugees in Kurdistan falls largely within a

175 range of QOL scores that have been reported from other samples. In summary, the scores among

176 the current sample are: (a) statistically significantly lower than general population norms

177 (Sevington,et al., 2004) for three QOL domains (physical, psychological and environment) and

178 Gaza Strip refugees (Eljed et al., 2006) on two QOL domains (physical and psychological); and

179 (b) statistically significantly higher than West Africa refugees (Akinyemi, et al., 2012) on all the 
180 QOL domains, Gaza Strip refugees on one QOL domain (environment), and general population

181 norms on one domain (social relationships).

182 A key finding from these comparisons is that Syrian refugees score higher than general

183 population norms on social relationships QOL. On face value, this suggests that Syrian refugees

184 report being satisfied with their personal relationships and friendships more than those in the

185 general population. The explanation for this difference may be that the current sample comprises

186 many individuals who have moved away from the conflict in Syria with their family and friends.

187 Therefore, the higher scores reflect a shared experience and purposeful support within a current

188 social network that has been heightened in the context of the current conflict, whereas this level

189 of social support which would not necessarily be present for many members of a general

190 population as it would not be required. It is worth noting that the statistical effect size of this

191 higher score is negligible (a magnitude that is less than small $[d=.2]$ ) and therefore any

192 statistical significant difference could be attributed to sample size. Moreover, there may be a

193 concern about making the comparison while omitting of one of the items from the scale, although

194 the scoring of the WHOQOL-BREF allows for the omission of items, and we have made a

195 comparable alteration to the population mean scores. Notwithstanding those caveats, the current

196 findings suggest that, even if the statistically significant higher difference is not robust, the social

197 relationships QOL scores compare favorably (by not being statistically significantly lower as with

198 the other QOL domains) to the population mean.

199 Another key finding is that Syrian refugees scores higher on environment QOL than the

200 other two refugee samples. This suggests that those respondents in the Kurdistan camps are

201 relatively more satisfied with the living conditions, and access to health and transport services to

202 respondents from the other two refugee camps at the time of those surveys. Therefore, it seems

203 that the environmental provisions made by the United Nations Refugee Agency in the camp could

204 be viewed as favorable. 
206 terms of the physical and psychological QOL domains, largely because these scores are lower to

207 a large effect size than those means reported among Gaza Strip refugees. It is likely that the

208 recency of the conflict in Syria and movement to the refugee camps has led to heightened levels

209 of health and psychological problems, however, as lower physical and psychological QOL can be

210 indicative of stress-related disorders (Carlsson et al. 2006; Fazel et al., 2005) this requires further

211 investigation. Therefore this finding indicates that if there is current concern for policy makers or

212 researchers, there may be a need to prioritize aspects of physical and psychological QOL among

213 Syrian refugees.

214 Despite these speculations, it is important that seeking any exacting social or policy

215 analysis in these comparisons is mostly redundant to the immeasurable variance in the nations,

216 context and time periods considered. However, the current findings do provide some key

217 indicators to QOL among Syrian refugees in Kurdistan, in terms of comparisons to the general

218 population and other refugee camps. Namely social relationships and environmental QOL

219 circumstances are relatively satisfactory, but if further investigation is needed, then a key focus

220 might be the consideration of physical and psychological QOL. 
222 Akinyemi, O.O., Owoaje, E.T., Ige, O.K., \& Popoola, O.A. (2012) Comparative study of mental

223 health and quality of life in long term refugees and host populations in Oru-ljebu,

224 Southtwest Nigeria. BMC Research Notes, 5, 394. doi: 10.1186/1756-0500-5-394.

225 Carlsson, J.M., Olsen, D.R., \& Mortensen, E.L. (2006) Mental health and health-related quality

226 of life: A 10-year follow-up of tortured refugees. The Journal of Nervous and Mental

227 Disease, 194(10), 725-731. doi: 10.1097/01.nmd.0000243079.52138.b7.

228 Cohen, J. (1988). Statistical power analysis for the behavioral sciences (2nd ed.). Hillsdale, NJ:

$229 \quad$ Erlbaum.

230 Eljed, A., Mikolajcyk, R. T., Kramer, A. \& Laaser, U. (2006). Health-related quality of life in

231

232 diabetic patients and controls without diabetes in refugee camps in the Gaza strip: a crosssectional study. BMC Public Health, 6, 268 doi:10.1186/1471-2458-6-268.

233 Fazel, M., Wheeler, J., \& Danesh, J. (2005). Prevalence of serious mental disorder in 7000

234

235

236

237

238

239 refugees resettled in western countries: a systematic review. Lancet, 365(9467), 13091314. doi: 10.1016/S0140-6736(05)61027-6.

Gerritsen, A.A.M., Bramsen, I., Deville, W., van Willigen, L.H., Hovens, J.E. \& van der Ploeg, H.M. (2006). Physical and mental health of Afghan, Iranian, Somali asylum seekers and

240

241 refugees living the Netherlands. Social Psychiatry and Psychiatric Epidemiology, 41(1), 18-26. doi: 10.1007/s00127-005-0003-5.

242 Preliminary population norms and effect sizes. Social Indicators Research, 77(1), 37-59.

243 Matanov, A., Giacco, D., Bogic, M., Ajdukovic, D., Franciskovic, T., Galeazzi, G.M., Kucukalic, 244 A., Lecic-Tosevski, D., Morina, N., Popovski, M., Schutzwohl, M. \& Priebe, S. (2013). 
245 Subjective quality of life in war-afected populations. BMC Public Health, 13, 624. 246 doi:10.1186/1471-2458-13-624.

247 Ohaeri, J.U. \& Awadalla, A. W. (2009). The reliability and validity of the short version of the

248 WHO Quality of Life Instrument in an Arab general population. Annals of Saudi $249 \quad$ Medicine, 29(2), 98-104.

250 Sevington, S.M., Lofty, M., \& O'Connell, K.A. (2004). The World Health Organization's 251 WHOQOL-BREF quality of life assessment. Psychometric properties and results of the 252 international field trials A Report of the WHOQOL Group. Quality of Life Research, 253 13(2), 299-310. doi: 10.1023/B:QURE.0000018486.91360.00.

254 Tang, S.S. \& Fox, S.H. (2001). Traumatic experiences and mental health of Sengalese refugees. 255 The Journal of Nervous and Mental Disease, 189(8), 507-512. doi: 10.1097/00005053$256200108000-00003$.

257 The WHOQOL Group (1995). The World Health Organization Quality of Life Assessment 258 (WHOQOL): Position paper from the World Health Organization. Social Science and 259 Medicine, 41(10), 1403-1409.

260 United Nations Refugee Agency (2013). UNHCR Registration Trends for Syrians (02 April).

261 Resource document. United Nations Refugee Agency.

262 http://data.unhcr.org/syrianrefugees/country.php?id=103. Accessed 10 March 2013.

263 United Nations Refugee Agency (2014). UNHCR Registration Trends for Syrians (28 February).

264 Resource document. United Nations Refugee Agency.

265 http://data.unhcr.org/syrianrefugees/country.php?id=103. Accessed 1 March 2014.

266 United Nations Refugee Agency (2014). UNHCR Registration Trends for Syrians (05 March).

267 Resource document. United Nations Refugee Agency.

268 http://data.unhcr.org/syrianrefugees/country.php?id=103. Accessed 10 March 2014. 
269 United Nations Refugee Agency (2014c). Syria Regional Response Plan Iraq. Resource

270 document. United Nations Refugee Agency http://www.unhcr.org/syriarrp6/docs/syria-

$271 \quad$ rrp6-iraq-response-plan.pdf\#A. Accessed 10 $0^{\text {th }}$ March 2014.

272 United Nations Refugee Agency Information Management Unit (2014). UNHCR Monthly

273 Information Kit (March, 2014). Resource document. United Nations Refugee Agency.

274 http://data.unhcr.org. Accessed 10 $0^{\text {th }}$ March 2014.

275 WHOQOL group (1998). The World Health Organization Quality of Life Assessment

276 (WHOQOL): development and general psychometric properties. Social Science and

277 Medicine, 46(12), 1569-1585.

278 World Health Organization (1997). WHOQOL: Measuring Quality of Life. Resource document.

279 World Health Organization. http://www.who.int/mental_health/media/68.pdf. Accessed 31 $280 \quad$ March 2014. 


\section{Table $\mathbf{1}$ (on next page)}

Table 1

Mean (SD) score comparisons for WHOQOL-BREF domain scores (range 4-20) between Kurdistan refugees and adults across 23 countries $(n=11,830)$ from Skevington et al. (2004). 
Table 1

Mean (SD) score comparisons for WHOQOL-BREF domain scores (range 4-20) between Kurdistan refugees and adults across 23 countries (n =11,830) from Skevington et al. (2004).

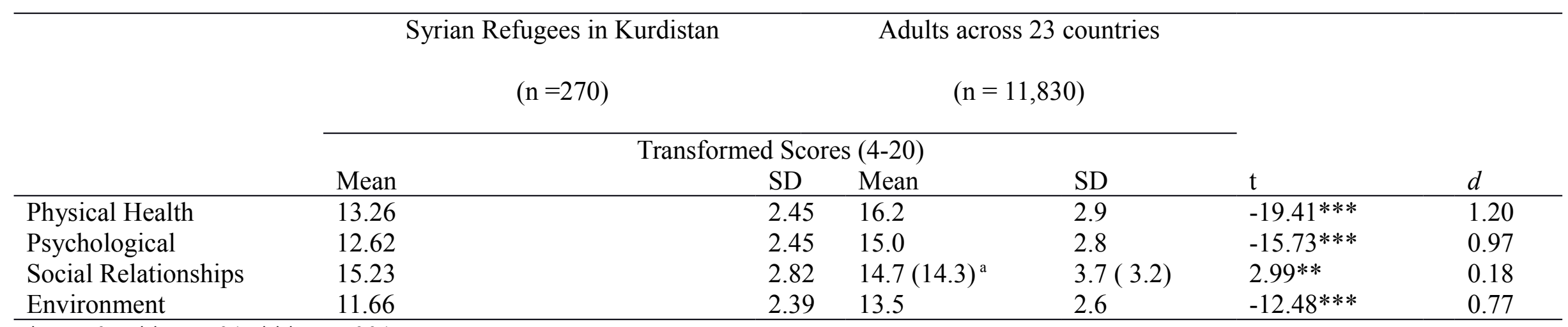

$* \mathrm{p}<.05 ; * * \mathrm{p}<.01 ; * * * \mathrm{p}<.001$

${ }^{\text {a }}$ Original mean (SD) scores provided by Skevington et al. (2004) in brackets. 


\section{Table 2 (on next page)}

Table 2

Mean (SD) score comparisons for WHOQOL-BREF raw scores between Syrian refugees residing in Kurdistan and Refugees residing in West Africa. 
Table 2

Mean (SD) score comparisons for WHOQOL-BREF raw scores between Syrian refugees residing in Kurdistan and Refugees residing in West Africa.

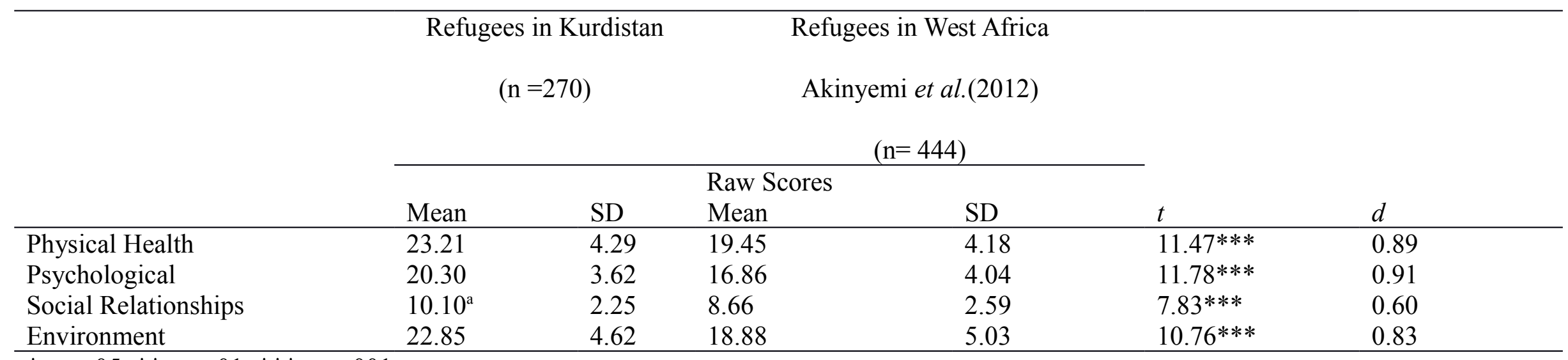

$* \mathrm{p}<.05 ; * * \mathrm{p}<.01 ; * * * \mathrm{p}<.001$

${ }^{\text {a }}$ Raw score for 2 items is weighted for comparison against a 3 item score. 


\section{Table 3(on next page)}

Table 3

Mean (SD) score comparisons for WHOQOL-BREF transformed Scores (0-100) between Syrian refugees residing in Kurdistan and Refugees residing in the Gaza strip 
Table 3

Mean (SD) score comparisons for WHOQOL-BREF transformed Scores (0-100) between Syrian refugees residing in Kurdistan and Refugees residing in the Gaza strip

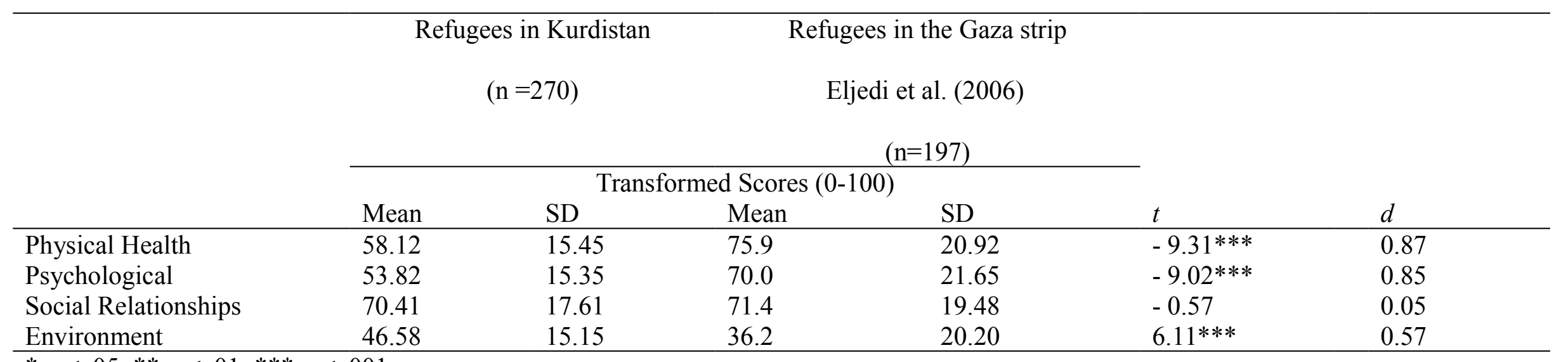

$* \mathrm{p}<.05 ; * * \mathrm{p}<.01 ; * * * \mathrm{p}<.001$ 